\title{
Ergonomics in Product Design
}

\author{
Yang Xi-Hui ${ }^{1, a}$, Zhu Yuan-Peng ${ }^{2, ~ b ~ * ~}$ \\ ${ }^{1,2}$ School of Mechano-electronic Engineering, Xidian University, Xi'an Shaanxi, 710071, China \\ axhyang@mail.xidian.edu.cn, ${ }^{b}$ zhujunyuanpeng@163.com
}

Keywords: Ergonomics; 3D Printing; Ergonomic Evaluation; Product Design

Abstract. In this article, according to the social science and technology development, through continuous improvement of the key technology of modern product design: ergonomics, 3D printing technology, man-machine ergonomic evaluation, etc. to gradually make the product design process more perfect and mature, making the process of industry product design more scientific and people-oriented. Finally with the analysis on the example of a small size washing machine, expounds the scientific and efficient product design process in line with today's science and technology trends.

\section{Introduction}

According to the social development, technological progress, product updates, the accelerating pace of life and a series of the influence of social and physical factors, people not only enjoy the material life at the same time, but also pay more attention to the product's experience in convenient, comfortable, reliable, value, safety and efficiency, etc. so there is a humanized design problem often mentioned in the product design ${ }^{[1]}$. Ergonomics is a discipline which is establishment of the design based on human nature, it is a multi-disciplinary activity, dedicated to the collection of related information about the human body, and the information used in design, products, and equipment to the workplace.

This article is on the premise of basic sciences, integrating into modern science and technology, made the industrial product design process more perfect and mature, through the human operating data of ergonomics, with the help of the computer aided design of virtualization, 3D printing technology, from this it shorted the production cycle, and reducing the production cost; finally combination of ergonomics evaluation system, to obtain the ideal product of people-oriented.

\section{The key disciplines of modern product design}

Modern product design is a creative design process which contain of technology, culture, practical, etc. A mature and perfect product design often need multi-disciplinary technical support, which generally includes the following key technology disciplines: ergonomics, 3D printing technology, man-machine ergonomic evaluation, etc.

\section{Ergonomics}

Ergonomics is on the basis of people's psychological, physiological characteristics, from the view of system engineering, analysis and Study on the interactions between people and machines, people and the environment as well as mechanical and environment, to design a simple operation and labor saving, safe and comfortable products, in order to make the human - machine-environment reach the best engineering system provides the scientific basis of theory and method.

Ergonomics research in the design of man-machine system, focusing on the comprehensive consideration of the people's property and ability, and limit the effect by machines, operating and environmental conditions. At the same time, ergonomics also focus on the study of human's training, man-machine system design and development, and the biological or medical problems which is related with human-machine system. The product should be designed to adapt to the surrounding environment, so the product should not lose its original utility in the environment or effect on the original function or not appropriate the environment, it should not go against people's operation. 
The development of computer graphics, virtual reality and high performance graphics system, it make the man-machine engineering is no longer confined to the traditional accumulated data application category, but make full use of the high performance graphics computing ability and establish the virtual environment simulation and evaluation platform which contain of 3D graphical, interactive, realistic, and evaluation of design from the space station, navigation device, ships, vehicles, it has become an important link in the product life cycle ${ }^{[2]}$.

\section{D Printing}

3D printing technology is the newest rapid prototyping device using light curing and paper lamination technology. It is a simply kind of rapid prototyping technology, which is able to files based digital model, and use the powdered metal or plastic or other bonding materials, it is a technology through of layer printing mode to construct object ${ }^{[4]}$.

Because 3D printing can get product entities which has high accuracy, high utilization rate of raw materials, processing more different shapes complex form, and without the need for tools and fixture. therefore, it is more suitable for getting the initial entity prototype rapidly in product design stage, then according to the entity analysis we can quickly and better adjust design to get the product which matches the needs of people, It is a new method which can show and evaluate product design quickly.

\section{Ergonomic Evaluation}

The final form of a product is based on virtual model and 3D printing technology to produce the entity with the help of computer aided design, after a certain degree of adaptability evaluation, and according to the evaluation results, we optimize and modify the design scheme; It is a "design--evaluation--redesign" process which is iterating many times. And we make man-machine ergonomic evaluation respectively on the stage of computer virtual design and 3D printing the entity. As a result, we cut down the design time.

To construct the evaluation system with scientific theory and method, and reasonable selection of evaluation methods, from this we can get a proper man-machine ergonomic evaluation way. The evaluation function method which we generally used are a simple evaluation method and multi-factor comprehensive evaluation method.

Product evaluation have many factors, so we generally use in combination with several methods from multi-factor comprehensive evaluation method, The main use multi-factor comprehensive evaluation method is Fuzzy Comprehensive Evaluation (FCE) and Analytic Hierarchy Process (AHP).

By using the multi-factor comprehensive evaluation method we can fully and accurately according to the evaluation function to select the products to meet user specific expectations. This paper is based on the washing machine as an example for analysis, according to the characteristics of washing machine, and considering the operation's safety, convenient, easy to use, conform to the environment and other related man-machine engineering characteristics to make the related man-machine evaluation system.

\section{The process of product design based on Ergonomics}

The design under the guidance of the "people-oriented" design concept, and through the key technology of modern product design disciplines, we make the man-machine ergonomic design of the product. From the products, we know that only the proper design may be the best.

According to the ideas and methods of modern product design, and determined a design flow chart based on man-machine Ergonomics (Fig.1). In this product design process to guide and design the product, we can get the ideal design better and more quickly. 


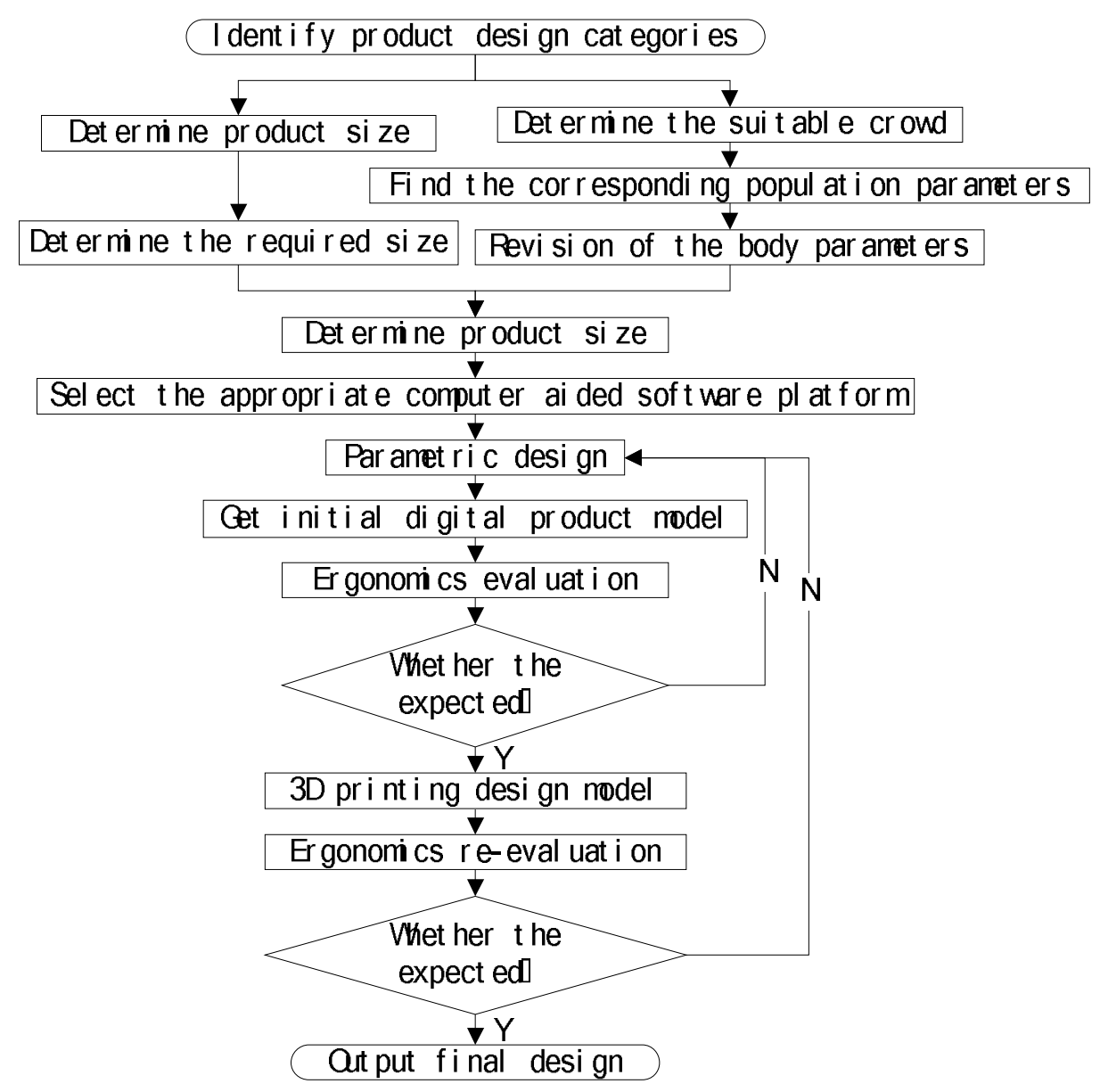

Fig.1 Design flow chart

\section{Example Analysis}

The fast-paced modern city life style and the per capita living space narrowing, make the small size objects become necessities of life at home. This article is in this background, we design of small size washing machine as an example for correlation analysis.

The design of small size washing machine is according to the design process and the steps in fig.1. Starting from the point of view of "man", we need to collect the body's essential data. Because it is designed for the small size washing machine, the size of the operation button should easy to operate, So the body's data collection is mainly concentrated in the palm size ( for convenient operation button), and the best human hand activity area (convenient for users pick or place clothes in a comfortable posture and do other operations).

From the point of view of "machine", we need to pay attention to Local design: Protective cover's safety in washing machine working condition; we can't open the protective cover in washing process or if open it while the machine should stop working immediately; Button for easy operation; The button size should match the human hand activity area, to avoid the probable misoperation because of the size is too small; The washing machine inner tank's size should easy to pick and place clothes; and we should consider the washing bucket size, capacity, etc.

From the point of view of "environment", the small size washing machine should be merge together with the environment, should not affect the surrounding environment, and should not be disturbed by the surrounding environment influence. At the same time the colors' choosing should consider the surrounding color, and thus giving people a comfortable visual experience.

In conclusion, from the point of view of the man-machine ergonomics, and combined with the practical design intention and users' aesthetic visual experience, from this we design the small washing machine, and the design modeling as shown in fig.2. 


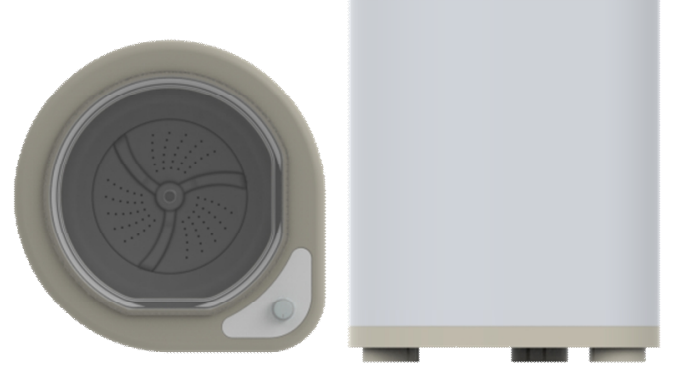

Fig.2 Top and front view

The size of the machine is: $420 \mathrm{~mm} \times 420 \mathrm{~mm} \times 580 \mathrm{~mm}$.

Through the computer aided industrial design software, and the preliminary design ideas, we establish the digital model; Based on this design, we make the man-machine ergonomic evaluation according to the product design process: By using the Fuzzy Comprehensive Evaluation (FCE) method as the fitness function to evaluate the digital model. and made the relevant evaluation system form (as shown in Table 1) for evaluation of the expected degree of correlation.

Table 1 The small washing machine overall design evaluation form

\begin{tabular}{|c|l|c|c|}
\hline No & \multicolumn{1}{|c|}{ Evaluating indexes } & $\begin{array}{c}\text { Weighting } \\
\text { coefficient }\end{array}$ & $\begin{array}{c}\text { Produc } \\
\mathrm{t}\end{array}$ \\
\hline \multirow{3}{*}{1} & 1.1 Space dimension is balanced & $0.2 * 0.3$ & \\
& 1.2 The texture matches function & $0.2 * 0.3$ & \\
& 1.3 The unified form and function & $0.2 * 0.4$ & \\
\hline \multirow{2}{*}{2} & 2.1 Important controls in the best position & $0.2 * 0.5$ & \\
& 2.2 Operation conforms with force rules & $0.2 * 0.5$ & \\
\hline \multirow{3}{*}{3} & 3.1 Unique style & $0.2 * 0.4$ & \\
& 3.2 The proportion of coordination & $0.2 * 0.3$ & \\
& 3.3 Neat shape, Moderate connection & $0.2 * 0.3$ & \\
\hline \multirow{5}{*}{4} & 4.1 Button's use safety & $0.2 * 0.3$ & \\
& 4.2 Protective cover's use safety & $0.2 * 0.3$ & \\
& 4.3 The working state's use safety & $0.2 * 0.4$ & \\
\hline \multirow{5}{*}{5} & 5.1 Its color's harmony & $0.2 * 0.3$ & \\
& 5.2 The suitability of the color and use & $0.2 * 0.3$ & \\
& conditions & $0.2 * 0.4$ & \\
& 5.3 Color balance, stable sense & & \\
\hline
\end{tabular}

Choosing a number of groups ( such as designers, users, etc.) to take part in the survey through the above table parameters. Setting all kinds of groups' evaluation weights scientifically, according to the weighted average of each kind of groups, getting the final test sample numerical. According to adjust the design of successive iteration by the every times' feedback information, until got the optimal digital model; After this we get the generation of entity rapidly through the 3D printing technology, according to the real entity's real operation evaluation to adjust the digital model to get the optimal entity; and final get the perfect product design. The final entity view is as follows: 


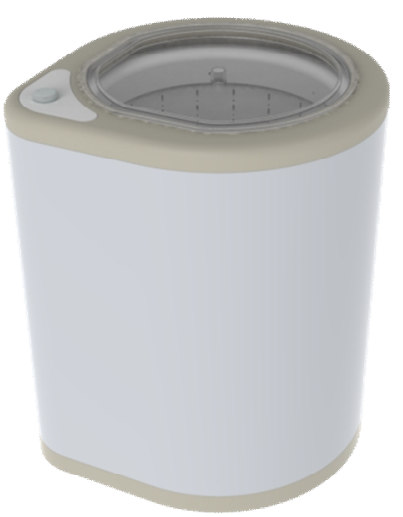

Fig.3 The final entity picture

\section{Conclusion}

With the progress of science and technology, Product design gradually combine with many key technology of man-machine ergonomics, ergonomics evaluation and 3D printing technology, etc. It forms a new, scientific and efficient product design process which is based on ergonomics, and it Supplement and improve the shortcomings of the previous design because its iterative optimization evaluation unlink the entity, or the shortcomings of time-consuming and material-consuming during machining process in the process of entities evaluation. Through the example of the small size washing machine verified the design process, Developing a new idea of product design based on ergonomics.

\section{References}

[1] http://baike.baidu.com/link?url=vneMpDdj4zNIBB1Gyu3991Es5ecLsxCOHYGj1GSkF4nq-ITT Br-ENX-_D70yEyRbAv-xLgmuqKpQjhpsH9Ao5K,2014.11.29

[2] Luo Shijian, Sun Shouqian, Tang Mingxi, Pan Yunhe. Study on computer-aided ergonomics design [J]. Journal of Zhejiang University. 2005, 39 (6) :805 809,829

[3] Yang Haicheng, Lu Changde, Yu Suihuai. Computer aided industrial design[M]. BEIJING INSTITUTE OF TECHNOLOGY PRESS.2009

[4] http://baike.baidu.com/view/4117826.htm?fr=alad din,2014.11.29

[5] Xu Meng,Sun Shouqian. Progress of Research on Computer-Aided Ergonomics[J]. JOURNAL OF COMPUTER-AIDED DESIGN \& COMPUTER GRAPHICS. 2004, 16 (11):1469 1474

[6] Liu Wei. Actuality and Development in Human-Machine Engineering[J].Haidian UniversityJournal. 2003, 64(4): 77 81

[7] Chai Chunlei, Huang Qi, Dong Zhanxun, Sun Shouqian. Home Appliance-Oriented Ergonomics Analysis and Evaluation System[J]. JOURNAL OF COMPUTER-AIDED DESIGN \& COMPUTER GRAPHICS. 2006, 18(4): 580 584

[8] Somadeepti N.Chengalur, Suzanne H.Rodgers, Tomas E.Bernard. KODAK's Ergonomic Design for People at Work [M]. Second Edition. John Wiley \& Sons,Inc , 2003

[9] Karwowski W, Genaidy A M, Asfour S S. Computer-aided ergonomics: a researcher's guide [M]. London: Taylor\&Francis, 1990

[10]Raschke U, Schutte L, Chaffin D B. Simulating human: Ergonomic analysis in digital environments [A]. Hand Book of Industrial Enginering. New York: J Wiley\&Sons, 2001

[11]Mattila Markku. Computer aided ergonomics and safety--A challenge for integrated ergonomics [J]. International Journal of Industrial Ergonomics, 1996, 17(4): 309 314 
[12] Sun Shouqian, Tang Ming, Pan Yunhe. Research on Ergonomics-Based Layout Design[J]. JOURNAL OF COMPUTER-AIDED DESIGN AND COMPUTER GRAPHICS. 2000, 12(11): $870 \sim 872$

[13]Kleiner Brian M . Macroergonomic analysis of formalization in adynamic work system [J]. Applied Ergonomics, 1998, 29(4): 255 259

[14]Ashraf Shikdar, Saeed Al-Araimi, Bill Omurtag. Development of a software package for ergonomic assessment of manufacturing industry [J].Computers \& Industrial Engineering, 2002, 43(3): 485 493

[15]Qiao Yimin, Wang Jiamin. Application of 3D Printing Technology in Container Molding Design [J]. PACKAGING ENGINEERING. 2012, 33(22): 68 71 